\title{
SOBRE "SOCIOLOGÍA DE LA CULTURA: LA DECONSTRUCCIÓN DE LO MAPUCHE”, DE ALDO MASCAREÑO
}

\author{
Jorge Larraín
}

\begin{abstract}
Este artículo comenta críticamente el texto de Aldo Mascareño publicado en este número. No discute la crítica de Mascareño a un concepto esencialista de cultura, pero sí su pretensión de deconstruirlo hasta que quede conceptual y teóricamente exangüe. Tras pasar revista a las dos tradiciones que subyacerían a la pérdida de valor analítico del concepto de cultura, a saber, la sociología sistémica de Luhman y el postmodernismo o postestructuralismo, el comentario sugiere una interpretación del concepto de cultura que sea capaz de seguir rindiendo teóricamente.
\end{abstract}

Jorge LaRRaín. Doctor en Sociología, Universidad de Sussox, Inglaterra. Director de Investigación y Publicaciones, Universidad Alberto Hurtado. Autor de numerosas publicaciones sobre cultura, modernidad e identidad en América Latina y teorías de la ideología.

N. del E.: Sobre los resultados de la encuesta mapuche realizada por el CEP (2006), véanse en esta edición los trabajos de Fernando Zúñiga, Eduardo Valenzuela, Ignacio Irarrázaval y M. de los Ángeles Morandé, Aldo Mascareño, Rolf Foerster y Sonia Montecino, Juan M. Ossio, y la presentación de Carolina Segovia y Lucas Sierra. 
D ebo empezar diciendo que el artículo de Aldo Mascareño es extremadamente interesante y tiene el mérito de tener una tesis central provocativa, claramente expresada y bien argumentada, que hace de hilo conductor de todo el análisis y que permite levantar temas importantes de discusión. Todo artículo que hace pensar es ya muy bueno. Un mérito adicional es el intento por articular un análisis histórico y teórico sobre los conceptos de cultura e identidad y un análisis empírico sobre la cultura mapuche basado en la encuesta que ha conducido recientemente el CEP. Esto no es nada de fácil, pero Aldo logra un resultado coherente y consistente. Pero, como en todas las cosas, hay también la posibilidad de soluciones teóricas alternativas. Trataré libremente de explorar algunos de los supuestos desde los que el artículo parece partir e intentaré entregar argumentos críticos en algunos puntos y propositivos en otros. De todos modos reconozco un sesgo y me disculpo por él: me fue más fácil comentar las partes teóricas que las aplicadas. Y en esto acepto que puedo no haber estado a la altura de lo que Lucas Sierra o Aldo Mascareño esperaban de mí: una discusión centrada en el problema mapuche y secundariamente en las implicaciones teóricas. Si esa expectativa existía, advierto que yo he invertido los términos.

Aldo sigue el camino más difícil: en vez de utilizar un concepto o teoría para iluminar datos de la encuesta, que es lo que normalmente los sociólogos harían, parte por descartar el rendimiento teórico del concepto de cultura e intenta fundamentar esto en los propios resultados empíricos de la encuesta que parecen no discriminar entre lo mapuche y lo no mapuche. Pero como de alguna manera todavía necesita del concepto para explicar algunas cosas de los mismos resultados, reafirma el concepto pero en su función política.

Aquí hay todo un campo rico de elementos para analizar y discutir. De ellos tomaré solamente algunos que me provocaron algunas reflexiones.

Antes que nada, es obvio que merece algún comentario la tesis fuerte del trabajo, que la cultura ha perdido como concepto su poder explicativo en las sociedades modernas debido a que sus constelaciones de sentido son cada vez más transversales, supraterritoriales, interpenetradas y multidependientes. Sobre esto me asaltan muchas dudas. Una cosa es criticar un concepto esencialista de cultura, aceptar la creciente porosidad de los mundos simbólicos, advertir contra las pretensiones totalizantes, uniformizantes y sobre-integradas de ciertas versiones del concepto, otra muy distinta es deconstruirlo hasta su muerte teórica y llegar a sostener que hablar de cultura es hablar de un vacío. Vacío, por supuesto, al nivel analítico societal, que no impide que actores individuales lo usen para fines políticos. 
Detrás de esta propuesta parece haber dos argumentos claves. Por un lado está la distinción fuerte entre sociedad e individuo como mundos aparte, que cree poder prescindir del concepto de cultura. Más precisamente, entendí que el concepto de cultura podría tener algún sentido en las sociedades segmentarias del pasado, pero no en las sociedades modernas altamente diferenciadas donde ya no existe una unidad simbólica necesaria para la reproducción del todo social sino que los individuos se regulan por mecanismos de inclusión y exclusión en diversas esferas.

Por otro lado está el argumento de la iterabilidad simbólica de los signos o de las constelaciones de significados. Lo que esto significa no es tan claro en el texto. Pero la idea de iterabilidad tiene algunas fuentes conocidas que, a partir del supuesto que todo signo debe ser repetible, le ponen límites a la intencionalidad del autor como responsable de la significación. Existiría una especie de ley de la contaminación que impediría decidir entre actos intencionales y repeticiones parasíticas que nunca pueden ser excluidas. Así entonces la cultura o campo de significación carecería de significados fijos o referidos a algo más allá del discurso. Los significados se autonomizan y dependen más bien de la interrelación de significantes, de estas repeticiones o citas que inevitablemente interfieren los significados intencionados.

A la distinción radical entre sociedad e individuo se agrega la disolución del sujeto, el que deja de ser el autor que maneja el sentido de lo que propone, y es más bien el mismo producido o determinado por discursos o textos que él no controla y que adquieren vida propia. Pero esos textos no tienen en sí mismos su significado, sino que se intersectan con otros textos que producen nuevos textos llegando así a esa famosa intertextualidad que adquiere vida propia y significados que no pudieron preverse. Los significados se hacen así inestables y ambiguos. Si la cultura se entiende como una serie de textos, entonces estamos diciendo que la cultura es inherentemente plural y abierta a un número infinito de interpretaciones. De aquí surge la idea de deconstrucción como una manera de leer que busca otros textos dentro de un texto, cancelando así los significados intencionados u obvios en un proceso sin fin. De allí que la cultura deje de tener sentido único o definible. Si todo es posible, entonces el concepto deja de tener utilidad.

De este modo dos tradiciones parecen confluir en la pérdida del valor analítico del concepto de cultura, dos tradiciones que terminan por potenciarse aunque son muy distintas: por un lado la sociología sistémica de Luhman donde se ubica el argumento que distingue entre sociedad e individuo y proclama la pérdida de la unidad simbólica de la sociedad. Por el 
otro lado el postmodernismo, o postestructuralismo, especialmente aquel que deriva de Derrida, que establece la iterabilidad del mundo simbólico y que desconecta la cultura de todo contexto externo al discurso.

El concepto puramente simbólico o discursivo (textual) de cultura que propone el postmodernismo, al eliminar su contexto y referencialidad externa, facilita el paso siguiente que es reconocer su inutilidad teórica. Frente a esta opción hay sin embargo otra, que puede evitar su vaciamiento afirmando el hecho de que las formas simbólicas se dan siempre en contextos y procesos históricos específicos y estructurados dentro de los cuales se producen, transmiten y reciben. Es lo que John Thompson ha llamado una concepción estructural de la cultura que siempre une significado a contexto. En otras palabras, lo que quiero decir es que la aparente falta de rendimiento analítico del concepto de cultura depende de un análisis particular de la cultura de origen postmodernista, que no tiene una necesidad absoluta. Con otra concepción u otros análisis los rendimientos podrían mejorar.

El artículo propone, además, un proceso parecido para el concepto de identidad que es tratado como intercambiable con el concepto de cultura. Aquí aparezco yo, entre otros, porque he escrito algunas cosas sobre identidad. Pero, en el contexto de la tesis que Aldo quiere demostrar, se interpreta lo que yo he dicho como un intento de deconstrucción del concepto de identidad que lleva a consecuencias similares: después de agregar yo dimensiones histórico-temporales, de hablar de versiones públicas, de criticar la idea de carácter nacional y de atacar los esencialismos, habría llegado a una identidad interpenetrada e inconsistente que da lugar a la pregunta de si algo así puede seguir siendo llamado identidad.

Cae también entonces el concepto de identidad, aunque eso no significa que no sea útil para algunos actores. Tomando a Stuart Hall en su momento más postmodernista, Aldo lo cita cuando dice que "las identidades emergen de la narrativización del sí mismo, pero la naturaleza necesariamente ficcional de este proceso de ninguna manera socava su efectividad discursiva, material o política”. De aquí concluye que cultura e identidad son, o tal vez sólo sirven como, construcciones ficcionales autodescriptivas.

Tres comentarios sobre esto. Primero, identidad y cultura no sólo se vacían como conceptos sino que pierden toda diferencia entre sí. Me parece que es necesario distinguir entre identidad y cultura. Concedo sin embargo que si estos dos conceptos han muerto, tiene menos importancia detenerse a pensar cuál es la diferencia entre los dos cadáveres. Pero a mí, que todavía sospecho que están vivos, o tengo algún interés en rescatarlos de cualquie- 
ra ejecución sumaria, sí que me importa establecer su diferencia y su modo de relación. Y curiosamente hacer esto puede servirle a Aldo para apoyar, en forma modificada su tesis sobre el uso político de los conceptos. Porque a mi modo de ver, por definición, la identidad es una manera de movilizar algunas formas simbólicas presentes en la cultura para construir un relato sobre el sí mismo tomado como objeto. Mientras la cultura es la estructura general de significados incorporados en las formas simbólicas en contextos precisos, la identidad moviliza sólo algunos de esos significados para contar la historia del sí mismo, normalmente en función de algunos intereses o con alguna intencionalidad política en el caso de identidades colectivas. Aquí se inserta bien la idea de la lucha por el reconocimiento en la que diferentes grupos étnicos o movimientos sociales tales como los mapuches, las mujeres, los homosexuales, etc., usan su narrativa identitaria. Pero para mí es la identidad la que tiene ese aspecto de uso político más directamente, no tanto la cultura. Acepto, sin embargo, que no tiene tanta importancia que los actores o movimientos sociales invoquen a la cultura o a la identidad indistintamente. Ellos no tienen que ser precisos, pero nosotros, analistas, debemos distinguir.

En segundo lugar, estoy en desacuerdo con Hall que la narrativización del sí mismo es un proceso necesariamente ficcional, si es que por eso se entiende la ausencia de una base real de la narrativa. Hay una diferencia entre literatura y relato identitario, así como la hay entre literatura y teoría. Sabido es que Derrida elimina esa diferencia y todo pasa a ser literatura o más bien un género literario. No pienso que esto sea correcto y lleva a problemas muy serios en los estándares de evaluación de los contenidos y en los criterios de verdad. Como Habermas ha sostenido en su crítica a Derrida, la lógica queda sometida a criterios estéticos. No es que no pueda haber ficción en muchos relatos identitarios. La hay. Sabemos de la invención de tradiciones a las que se ha referido Hobsbawm. Pero no todo es reducible a la ficción: siempre existe el "esto es lo que hicimos juntos y que nos dio origen", o "esta es la forma en que hacemos las cosas", o "esta es la manera como afrontamos tal problema", que tiene una base en eventos o acciones reales.

En tercer lugar, el artículo plantea que "buena parte de los problemas con los conceptos de identidad y cultura estriba en que en sus formas más modernas, se los emplea como designación de un objeto de análisis y a la vez como indicación de una autodescripción o discurso de los actores”. Por mi parte no veo la necesidad de oponer estos dos modos de empleo, y pienso que, en el caso de la identidad, por ejemplo, en tanto autodescripción de actores, la identidad se constituye en objeto de análisis y viceversa, 
en tanto objeto legítimo de análisis se puede entender su uso autodescriptivo por los actores.

Con respecto a la parte más aplicada del artículo tengo sólo unos pocos comentarios. Lo primero que hay que decir es que en general el análisis de los datos está muy bien hecho, incluidos los gráficos y cuadros. Se logra utilizar los datos de la encuesta inteligentemente para sostener la hipótesis central del artículo.

Sin embargo, me surgen también algunas dudas. Se dice en la sección cuarta que "Si la cultura mapuche fuese un todo articulado, único e irrepetible, entonces habría que esperar una notable diferencia en sus respuestas en relación a la población no mapuche”. Yo creo que es mucho esperar esto, salvo desde un concepto esencial o psicologizante de cultura. Un concepto no esencialista de cultura, a pesar de que no tiene por qué esperar una notable diferencia en las respuestas al tipo de preguntas propias de las encuestas, si puede marcar grandes diferencias de significados simbólicos, si se sabe llegar a ellas. Por ejemplo, ¿cómo podría esperarse que a la pregunta "a qué debiese el gobierno dedicar un mayor esfuerzo: pobreza, empleo, inflación, sueldos" las contestaciones de mapuches y no mapuches fueran distintas? Para los dos la pobreza y el empleo tienen prioridad. Pero esto no significa que no pudiera haber diferencias culturales entre mapuches y no mapuches: la manera como viven la pobreza, la actitud frente a la búsqueda de empleo pueden ser muy distintas a pesar del acuerdo sobre lo que debe ser prioritario para el gobierno.

En esto yo creo que el propio Aldo tiene una intuición correcta cuando dice que probablemente la encuesta es el método menos indicado para constatar la iterabilidad simbólica. Yo diría, más precisamente, que es el método menos indicado para detectar diferencias culturales en la medida que siempre permanece en los niveles formales cuantificables y le cuesta penetrar en las modalidades o trasfondos diferenciadores de acciones aparentemente similares. Los chinos pueden estar comiendo hamburguesas McDonald's igual que los chilenos, pero esa igualdad formal puede ocultar mundos de significados simbólicos distintos.

Por ejemplo, fijémonos en la pregunta de la encuesta relativa a cuáles son las prácticas más importantes para mantener la cultura mapuche. Aldo dice que se hubiera esperado una alta diferencia entre mapuches y no mapuches pero que el resultado arroja una interpenetración casi perfecta en las pautas. En 10 de 13 opciones no existe diferencia alguna: por ejemplo hablar mapuche, conocer la historia, que el estado entregue tierras, que no se discrimine a los mapuches, etc. A mí esto no me sorprende tanto, no en razón de la iterabilidad simbólica, sino a causa del carácter formal y general 
de la pregunta de la encuesta. Una pregunta de este tipo sospecho que habría producido resultados iguales o parecidos si estuviéramos comparando chilenos y franceses, rusos y japoneses, o bosquimanos y norteamericanos. Esto no se debe tanto a una interpenetrabilidad cultural sino al carácter de la pregunta. Todas las culturas tienen bastante claridad acerca de la importancia de la lengua para la cultura propia, no cuesta mucho extender esa idea a otras culturas. Pero eso no significa que las diferencias culturales hayan desaparecido.

Ahora bien, en el caso mapuche hay un factor adicional que complica el análisis y que tiene que ver con que tanto el contexto como los referentes estructurales y los procesos en los que se inscribe la cultura han sido por mucho tiempo compartidos entre chilenos y mapuches. No hay una base territorial y estructural absolutamente autónoma de la cultura mapuche. De allí que sea cierto que, salvo en ciertos aspectos, las culturas mapuche y chilena se sobreponen o están interpenetradas. Pero esos aspectos que sobreviven como distintivos pueden ser movilizados en los relatos identitarios con una finalidad política en la lucha por el reconocimiento.

Para el artículo es inconsistente que aquellos a los que preocupa la mantención de la cultura mapuche esperen una mayor integración a la sociedad chilena porque sería ella la que debilitaría su cultura. Pero esto no es necesariamente inconsistente. Para mí indica un deseo de integrarse y de ser aceptado en la sociedad chilena pero con su diferencia cultural, con su identidad. Es lo que sucede con las personas de origen indio o paquistano en Gran Bretaña y los de origen algerino o marroquí en Francia. Buscan una integración que no amenace su identidad, que reconozca su contribución específica. Es desde esta posición que han surgido en Europa las concepciones acerca de las sociedades multiculturales. Tales concepciones descartan de partida una noción de cultura como un mundo cerrado y homogéneo, pero por otro lado también descartan la disolución final de toda diferencia cultural.

Quizás el punto esté en decidir si el número y calidad de las diferencias son suficientes y consistentes como para hablar de culturas diferentes, a pesar de que la homogeneidad total es imposible y quizás nunca fue posible, aun en el caso de sociedades segmentarias. Salvo casos de aislamiento total, siempre ha habido incorporación de formas simbólicas de otras culturas. Esto no elimina la posibilidad de distinguir entre diversas culturas. Pero dudo que las diferencias puedan ser simplemente establecidas o negadas por medio de encuestas que refieren, no a la totalidad social, sino que a una agregación de opiniones individuales aleatoriamente escogidas en un punto del tiempo. Doy un ejemplo comparando Chile con Inglaterra: mi ex- 
periencia viviendo allá me dice que una de las muchas diferencias culturales entre chilenos e ingleses es la forma como se maneja el duelo por la pérdida de un familiar muy querido. Mientras allá la persona se retrae y debe ser dejada sola para vivir su duelo, tanto que existe un adagio para los demás que dice "do not intrude into private grief", en Chile la gracia es la contraria: el doliente se apoya fuertemente en compartir su pena con los amigos. ¿Cómo podría llegar uno a esta diferencia de mundos simbólicos mediante una encuesta donde la pregunta misma ya presupone que uno sabe de la diferencia y sólo busca confirmación? Es posible que formalmente las ceremonias y los ritos funerarios externos no sean tan diferentes, sin embargo las personas viven su pena o hacen su duelo de una forma muy distinta. Si a este ejemplo uno pudiera agregar otros, en suficiente número y calidad, aunque nunca fuera posible en todos los aspectos, se podría perfectamente rescatar el concepto de cultura o de diferencia cultural. 